\title{
Development of Measuring the Efficiency using Economic and Environmental Resources, according to the basis Value and its Effect on Improving the Quality of Accounting Information
}

\author{
Hebatallah M. Alkashef \\ College of Business, \\ University of Jeddah \\ Department of Accounting
}

\begin{abstract}
Improving the quality of accounting information requires the need to take into account the efficient use of the organization for each of its current economic and environmental resources and expected to be obtained, since the efficient use of its economic resources is affected by the extent of its ability to use the available environmental resources efficiently; from an environmental and economic perspective, rather than adopting an economic perspective only when measuring its efficiency To exploit those resources.
\end{abstract}

The research aims to provide a guide for the organization's management that helps it create value for its available resources according to economic and environmental concepts together, and then achieve compatibility between environmental standards and the administrative perspective of environmental accounting, in order to help end a debate between supporters of value creation according to economic concepts, and those who advocate the need Taking environmental standards when searching for the facility to achieve the optimal use of the available resources.

To achieve the aim of the research and clarify the effect of adopting the criterion of efficient use of environmental resources on improving the overall performance of the organization, the efficiency of operational programs was analyzed by relying on value concepts, which affect the use of environmental resources, according to the entrance to value-based management.

The research relies on the economic concept of value trends, as an introduction to developing trends that make optimal use of available environmental resources; its application to measure the environmental impact of operational and production processes; and the analysis is based on clarifying the relationship between economic and environmental uses of available resources.

The results of the analysis indicated that the efficiency of the use of capital in accordance with economic standards does not necessarily mean achieving efficiency in the exploitation of available resources from an environmental perspective, or in other words, achieving the institution to efficiently use the available economic resources, does not mean achieving that optimal use of these resources from an environmental perspective; these results It supports the view that there is no confirmed relationship or a perfect match between the efficiency of the organization in the use of its resources from an environmental perspective, and its ability to create economic value; the research results also confirmed that the efficiency of the use of environmental resources is in fact a key factor, and not a catalyst for achieving consumption The effective available capital resources.

\section{General Terms}

Economic and environmental resources- Efficient use of economic and environmental resources- Value Creating

\section{Keywords}

Quality of accounting information, Economic and environmental resources- Economic perspective, Efficient use of environmental resources Value Drivers- Efficient use of capital, Value basis

\section{INTRODUCTION}

The increasing interest in sustainable development issues at the present time pushing the various economic units to seek to integrate environmental impacts in the decision-making process, which prompted administrative accountants, both in the field of research or practical practice to develop measurement methods and accounting reporting, with the aim of providing financial and non-financial data, to assist managers To improve the quality of decisions, so that goals can be effectively achieved (Horngren et al., 2016, p. 888); this requires the necessity to systematicall integrate environmental aspects into management accounting systems (Bennett and James, 1997; Burritt et al., 2002; Milne, 1996);

However, there are only a few father Two in the area of management accounting that adopts sustainable development issues (Thomson, 2007); this is evident from the scarcity of research that focused on applying the criterion of efficiency in exploiting the resources available to the organization from an environmental perspective (Burritt and Saka, 2006); where some believe that most accounting research It focuses on applying assumptions that achieve the organization's organizational goals from a traditional perspective (Gray and Bebbington, 2000). This motivated the researcher to try to link the concept of environmental efficiency and efficiency in the use of economic resources, in order to provide useful tools to support decisionmaking and achieve the highest efficiency in the exploitation of available environmental resources, rather than focusing on measuring capital efficiency only, which requires the need to focus on conducting an integrated assessment For the environmental and economic performance of the organization; this is achieved by designing a measurement framework that adopts the concept of integration between the environmental and economic perspective in the various decisions that are taken daily, based on the entrance to management according to value, and ensures the integration of environmental and economic aspects; And work to solve the problem of conflict between the environmental and traditional perspectives regarding the evaluation of performance within the framework of the concept of sustainable development. 
One of the concepts that has prevailed in the last two decades is the concept of efficiency (economic-environmental) as one of the concepts of integrated measurement of environmental and financial performance of institutions (Callens and Tyteca, 1999; Ciroth, 2009; Huppes and Ishikawa, 2005a, 2005b, 2009; Lamberton, 2005) The spread of the concept of efficiency (the economic environment) is due to the definition of the International Business Council for environmental effectiveness since the early nineties (Shmedini, 1992); where the concept of environmental economic efficiency was formulated in the seventies of the last century, when the proponents of this concept assumed that environmental resources were scarce and scarce, and therefore all seek Community units to exploit these resources in vain Layeh (Freeman et al., 1973; McIntyre an d Thornton, 1978), and the Efficiency Standard (Environmental Environmental) aims to demonstrate the efficiency of the organization in the use of scarce environmental resources. Economic activity and the unwanted environmental impacts of this activity (DeSimone and Popoff, 1998; Hahn et al., 2010; Huppes and Ishikawa, 2005a, 2005b; Reijnders, 1998; Saling et al., 2002). In many cases, environmental economic efficiency is seen as a broader concept, illustrating the extent to which economic unity contributes to the achievement of the sustainable development goals (Gladwin et al., 1995), due to the inclusion of some environmental elements that are difficult to quantify, such as biodiversity or social aspects. Of a qualitative nature, which prompted the researcher to try to develop an environmental economic efficiency measure as a tool to link environmental issues as a quantitative measure in order to provide the appropriate accounting information to improve the quality of decision-making.

Accordingly, it can be said that developing the decision-making process requires the necessity of taking into account the efficiency of the facility's use of available environmental resources, as well as its efficiency in using economic resources, as many of the current measures tend to focus on economic and financial performance in accordance with considerations of economic efficiency only, such as revenue at the top Money and added economic value. According to the concept of value-based management, performance efficiency refers to the ability to create value (Martin and Petty, 2017; Stewart, 1991); according to this logic, increasing profits is the most important factor from the perspective of management accounting systems (Ittner and Larcker, 2001 Malmi and Ikäheimo, 2003; O'Hanlon and Peasnell, 1998; Weißenberger and Angelkort, 2011; Will, 2010). The ability of an organization to create value for shareholders is determined by its ability to use the capital available to it more efficiently (Rappaport, 1986); in the same sense, it can be said that an organization's ability to use environmental resources more efficiently than other facilities increases their ability to create Sustainable value (Figge, 2001; Figge and Hahn, 2004, 2015).

The term environmental economic efficiency due to its use in discussions about the environmental performance of enterprises seeking to link environmental performance to economic performance; to achieve efficiency when making management decisions; where indicators of environmental economic efficiency provide information about activities that benefit the environment (Burritt and Saka, 2006). , P. 1266); with the adoption of the concept of profit for both parties, which means that the use of environmental resources should not lead to a loss for society and profit for shareholders, but the institution must strive to work under the rule of benefit "as long as the efficiency of the capital creates a response value To my shareholders Here, the effective use of environmental resources must be sought in order to create sustainable value for society "(DeSimone and Popoff, 1998; Orsato, 2006; Porter and van der Linde, 1995); thus the compatibility between creating economic value in terms of efficiency and use of resources means the environment On the other hand, it is necessary to apply the same value guidelines; however, this assumption has not been agreed upon or recognized, which has led to continued debate about whether the trend towards creating value for shareholders corresponds to the need to know the rights and interests of other parties such as The Workers of the Environment (McSweeney, 2007, p. 325); which requires the need to achieve a better understanding of the guidelines for efficiency in the use of capital on the one hand, and the efficiency of the use of environmental resources on the other hand, where the definition and clear comparison of capital and economic efficiency environmental efficiency leads to a deeper understanding of the relationship between the use of economic and environmental resources in the facility.

Through the concept of value measurement, and principles of value-based management, researchers and practitioners have sought to identify and define the drivers of maximizing capital use efficiency (Ittner and Larcker, 2001; Malmi and Ikäheimo, 2003). The most common way to determine this value is to analyze and classify efficiency ratios

The most well-known example of economic capital use efficiency is what is known as marginal capital adequacy which is Duponite (Keown et al., 2007) which divides the capital efficiency ratios into three which are sales margin, capital turnover and leverage; the same logic underlying the analysis of Economic efficiency; to measure the effective use of environmental resources (Figge and Hahn, 2004), and as an extension of what has been agreed upon, "value-based management" is adopted as inputs to create value for stakeholders.

Despite the large number of studies that dealt with measuring the efficient use of capital and economic value, and reaching common principles, the measurement of the effective use of environmental resources was not developed, which is what we seek to achieve through this research, and this is done through:

Dividing the environmental economic efficiency into its components, then defining valuable evidence that achieves efficiency in the use of environmental resources; and then providing an administrative guide on how to create a sustainable value through the use of economic and environmental resources.

Highlighting the conceptual relationship between economic value and sustainable value, and the relationship between the effective use of both economic and environmental resources in the facility.

Contribute to solving the prevailing debate between different perspectives on environmental accounting.

Accordingly, the research was divided into three sections. The first: deals with designing a general framework for a "valuebased" perspective on the use of environmental resources as a starting point for designing a "sustainable value approach"; this is followed by a discussion on developing value components and guidelines that achieve efficiency in the use of environmental resources in the second part, and the third part discusses most applications The conceptual and management reviewed.

\section{THE FOUNDATIONS OF BUILDING AN ENTRANCE TO MEASURE THE EFFICIENCY OF USING ENVIRONMENTAL AND ECONOMIC RESOURCES}

According to the "value basis," an institution creates value if the return on capital exceeds its cost. Financial management 
determines the cost of capital based on the opportunity cost; reflects the alternatives available to use capital to create value; in practice, the money market uses an average Return on capital to determine the opportunity cost of capital.

In establishing the sustainable value approach, Figge and Hahn relied on Green's proposal to apply the idea of an opportunity cost to resource use other than economic capital ((Figge, 2001; Figge and Hahn, 2004, 2015; Hahnetal, 2010) and the sustainable value approach was established on the assumption Companies need environmental and economic resources to generate a return that is the increase in the sustainable value achieved by the project, which represents an extension of the value-based perspective in the financial markets, by applying the idea of opportunity cost not only to economic capital, but also to the facility's use of resources Environmental; the value is said to touch Tadama shares some basic concepts with Value Based Management. It should be noted that building a sustainable value approach relies on the theory of resource dependence (Pfeffer and Salancik, 1978). Frooman defined resources as any value factor; as identified by Rothenburg et al. 2001, page 238)) Since everything has value, and based on this opinion, environmental resources have value, and they cannot be dispensed as inputs into their activities, such as economic resources, even if the mechanisms of obtaining them and converting them into natural resources. The capital is completely different. About economic capital.

Through the similarity between the entrance of economic capital and the shareholder value entrance, the sustainable value entrance adopts the opportunity cost of a given resource, to measure the efficiency of the organization's use of this resource compared to the market value, then the value achieved. Given that this analysis applies to different resources separately, this logic reflects the integrated nature of environmental and economic resources, and therefore the sustainable value approach relies on evaluation according to the value of sustainable performance that reflects revenue from the resource unit through alternative uses; and according to this logic it indicates The financial evaluation indicates that the sustainable value can be determined through the value resulting from the effective use of the institution's resources compared to the resource use efficiency in light of the average market efficiency. Therefore, the sustainable value is more comprehensive than other approaches that are concerned only with economic value by focusing on economic capital only.

To clarify the methodology upon which it was built when defining the components and directives of environmental economic efficiency; before addressing the main justifications, it is important to clarify the sustainable value approach in the context of conceptual development, where the sustainable value approach is seen as broader inputs, because they are included in both. The traditional approach based on the value realized from the exploitation of capital and economic resources, in addition to the environmental entrance that is concerned with measuring the value achieved from the use of environmental and social resources in the activity, which confirms the complementary nature of the types of measures; the cost of resources used by the unit in its activities, with the aim of creating value for shareholders, A sustainable value for society. In this regard, the sustainable value approach includes many aspects related to sustainable development, and at the same time, and in light of the methodology upon which it is based, the sustainable value approach includes a set of environmental and social aspects that can be quantified as resources.

Accordingly, it can be said that the sustainable value entry shares a shareholder value entrance with certain limits (Rappaport,
1986). However, the shareholder value approach only provides information about the value that can be created in light of the reference reference, while the sustainable value entrance does not provide any information On the absolute or full level of sustainability, which means that the sustainable value approach focuses only on the value resulting from the use of resources that can be subject to standards, and through this it shows the contribution of sustainable resources that were used only in the activity.

In light of the foregoing, it can be said that the basis of the proposed approach to sustainable value depends on the logic on which the value basis entries are based, but it applies to noneconomic resources when developing value guides in order to measure economic efficiency, by focusing on environmental and economic resources, the profitability share indicates the environmental resource associated with the activity, with the need for the brother in mind that the same logic potential for many other environmental resources with Quality and various social; as constraints on the use of the proposed entrance of sustainable value remains

\section{DEFINING AND DETERMINING FACTORS OF ENVIRONMENTAL AND ECONOMIC EFFICIENCY IN THE ORGANIZATION}

Measuring economic efficiency is the essence of the concerns of the various methods that sought to determine the economic value of the institution, through the ratio between the return achieved by the company and the size of working capital, which helped create the economic value. An increase in the explanatory power of the efficiency ratios for administrative purposes; these ratios were divided and categorized according to their components, and the clearest examples of this are the DuPont formula (Keown et al., 2007uz), which divided the ratio of return on equity to three elements, as shown in the following form:

Capital efficiency $=$ return $\div$ equity

$=($ Return $\div$ Sales $)($ Sales $\div$ Total Capital $)$ (Total Capital $\div$ Equity)

It is clear from the previous equation that the three components of capital efficiency include sales margin, capital turnover and leverage ratio, which reflect returns on equity, and help to analyze and manage the financial performance of the enterprise. Hence, it can be said that the DuPont model links the generation of profit and the use of capital to generate sales; and shows the ratio of total capital to equity; thus, the model highlights the reasons for the high capital efficiency, as it is affected by the amount of profit generated by sales, and the amount of sales per unit of capital Money (capital turnover) and percentage of equity to total capital (leverage ratio)

Some researchers believe that economic and environmental efficiency ratios can be defined in the same way as capital efficiency ratios (Callens and Tyteca, 1999; Huppes and Ishikawa, 2005a, 2005b; McIntyre and Thornton, 1978) are defined in light of the link between economic and environmental efficiency ratios using environmental resources; It is noted that the return number used here indicates a wide range that includes a control number that shows the economic results of the establishment's activities; in the context of an analysis of capital efficiency, profits and cash flows are often used as a return number; while in the analysis of environmental economic efficiency, depend on the required range and the explanatory strength of the efficiency indicators Economy Environmental friendliness, where various proposed returns numbers are used, 
often represented in sales, value added, or profits (Schaltegger and Burritt, 2000; Sturm et al., 2003). To increase the explanatory power of the enterprise's environmental economic efficiency ratios, the return on environmental capital is divided into Three simulation components of the DuPont model as shown by the following equation:

Environmental economic efficiency $=$

Return $\div$ environmental resources $=($ earnings $\div$ sales $)($ sales $\div$ capital) (capital $\div$ environmental resources).

Accordingly, the economic efficiency ratios are divided into three components, allowing to define trends in environmental economic efficiency. The first two ratios on the left hand side of the previous equation are similar to the DuPont model and refer only to the economic range of the company; the rate of return on sales reflects the profitability of the company's sales, which is equal to the profit margin that represents the value trend of the shareholder's value (Rappaport, 1986), and the second component indicates the turnover ratio of the head Money; which reflects the value of sales per unit of capital, the first two components of the component that show the return on economic capital (the return per unit of sales $x$ sales if the intensity of economic capital $=$ return to economic capital)

The third element in equation (2) shows the ratio of economic capital to environmental resources used by the company, and this element indicates that the facility not only needs economic capital, but also needs environmental resources; which is very similar to the leverage in the analysis The traditional DuPont in equation (1), which describes the capital used to increase the return on equity, i.e. the ratio of total capital to equity; the height of the lever is proportional to the ratio of total capital to equity, and according to the rationale behind the model, the Capital The user achieves the highest return on investment Ownership, increases the remorse expected return on total capital of the user cost of capital. The third component in equation (2) refers to the effectiveness of sustainability, represented in the ratio of environmental resources to economic capital, and the low effectiveness of sustainability to the environmental resources used in the facility in proportion to economic capital; then it can be said that the effectiveness of sustainability describes the relationship between economic capital And what it uses. The project has environmental resources; the rationale for this is that environmental economic efficiency will increase when the organization consumes less environmental resources compared to what it uses for economic capital; the three values of components of environmental economic efficiency ratios are represented in sales margin, leverage, financial sustainability, and leverage; Leverage and return on capital. This efficiency ratio division provides the difference between the economic component (return on capital generated by the first two components of value) and the environmental component (environmental leverage).
Like the shareholder's value, the sustainable value aims to evaluate the use of resources in light of alternative uses (the opportunity cost). The use of the resource generates a sustainable value when the revenue from its use exceeds the return from its use in the opportunity, and the performance of a Benchmark usually It is the average market performance, which is called opportunity cost, and while Hahn et al. (2010) to express the environmental economic efficiency of the facility compared to the reference efficiency; this research seeks to analyze many details that allow determining the directives and reasons related to the efficiency of the environmental economic performance of the facilities.

The value of the three components of environmental economic efficiency that are individually comparable separately with each component of the environmental economic efficiency of the market, which represents the reference comparison, where the figure shows each component of the value in company (C) with a similar component for the market that expresses On him, by reference comparison (d), that comparison generates three results, either for the company to be greater, less or equal to the reference standard, given each of the three components of the economic and environmental efficiency of the organization.

First: The sales margin is determined by the factors that generate profit for each unit of sales achieved by the company, and it may increase or less than the average reference comparison margin, and the higher sales margin indicates a better position for the facility.

Second: The rate of capital turnover is determined by the value of sales per unit of the company's capital, which may increase, decrease or equal the rate achieved in similar companies, and the rate of turnover of the higher capital indicates a better position for the enterprise.

Third: represented by sustainable leverage, determined by the ratio between the value of economic capital and the value of environmental resources used by the facility, which may increase, decrease or be equal to the reference percentage. From the environmental point of view, the lower environmental resources that the company uses compared to economic capital, and hence the increase in sustainable leverage indicates an increase in the rate of environmental economic efficiency.

The previous results are expressed graphically in Figure No. (1), where the y-axis represents the return on capital, which shows the economic component in the environmental economic efficiency of the facility; while the $\mathrm{x}$-axis is allocated to sustainable leverage; the economic value is achieved if the return on capital is the highest unit That is, the company achieves a return on capital greater than the benchmark; in this case it will appear above the horizontal line; and the facility that achieves higher units appears to the right of the vertical line in Figure (1). 


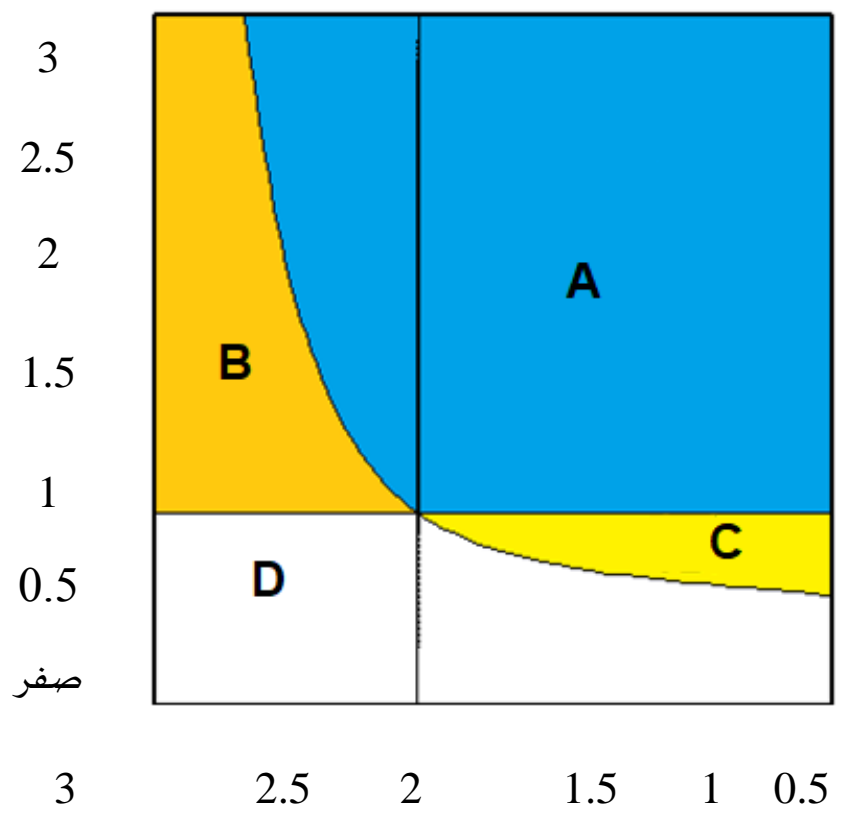

\section{Figure (1) Value generation using environmental and economic capital}

Environmental economic efficiency arises from the three components of value, and the curve shows the cases that generate return on capital (as depicted by the y-axis that represents the sales margin and the turnover rate of the capital) and the y-axis represents the sustainable leverage, and line (1) indicates the environmental economic efficiency of the facility When it equals the economic and environmental efficiency of the market, the company that shows the northeast curve (Blue Zone A) means that it has achieved higher economic-environmental efficiency than the market average (which represents the benchmark) and thus has achieved sustainable value.

Accordingly, it can be said that the establishment can achieve a level above the market average for environmental economic efficiency; and create value by using environmental resources through different combinations. For example, an establishment that uses more environmental resources compared to the companies corresponding to it will appear sustainable leverage, and will move to the side The left in Figure (1), that company needs to achieve high levels of return on capital to reach the benchmark in terms of environmental economic efficiency; and stay above the right side of the curve in Figure (1); in general the different combinations of return on capital and Sustainable leverage can achieve eco-economic performance.

The curve line shows the cases in which companies achieve environmental economic efficiency in light of the reference standard, and this occurs when the company achieves the reference standard in both return on capital and sustainable leverage (both equal 1) at the intersection of the horizontal and vertical line in Figure (1). Example An entity that uses twice the environmental capital per unit of economic capital as a benchmark comparison (sustainable leverage of (0.5) must increase the capital efficiency from the reference standard (return on capital of 2) to meet the economic economic efficiency similar to the reference standard.

Hence, it can be said that defining the components of environmental and economic value helps to identify four cases related to value creation through the use of economic capital and environmental resources, and Figure (1) describes those four cases depending on whether the company is making a profit from the cost of its alternative opportunities for capital Economic and / or environmental resources.

According to the "Management by Value" approach, the economic value is achieved if the company makes profits from the cost of its alternative opportunities for economic capital. This situation applies to all companies that achieve a return on capital that is higher than the reference standard, and are compatible with areas A and B in Figure (1) above the horizontal line; companies that create value from their use of environmental resources achieve profit opportunity cost benefits from their environmental resources, that is, when they achieve economic and environmental efficiency higher than the reference standard, and this is achieved when the environmental economic efficiency achieved for all elements is higher than the unit In Area A and C as it becomes clear From region (a) (northeast of the curve line) in Figure (1), the companies in that region make profit for an opportunity for both economic capital and environmental resources; in such cases the market average for environmental economic efficiency is exceeded; thus creating value Sustainable results in economic value creation; companies outside that region located north of the vertical line (1) achieve strong economic performance beyond their ability to achieve average leverage of sustainability, and their environmental economic efficiency is higher than market levels. Staying in Zone D is identical to companies that did not use neither economic capital nor environmental resources to create value.

\section{DISCUSS THE CONCEPTUAL AND MANAGEMENT FRAMEWORKS REVIEWED}

The research was based on the conceptual framework of the value perspective, which emerges from the administration of value according to value, as an input to support administrative decision-making related to accounting for environmental resources in addition to economic capital. Theoretical contributions are represented in trying to achieve better applications in managerial accounting; they contribute to achieving the goals of users in economic organizations and units with regard to social performance. 
Regarding excellence in performance as one of the goals of the facility, Malmi \& Granlund clarified the necessity to go beyond the narrow goal of maximizing economic efficiency or maximizing value to shareholders; to develop new theories in management accounting that take into account sustainable development, and other non-financial goals, which led them to Trying to develop theoretical foundations to clarify how certain methods can be used in managerial accounting to improve the quality of administrative decisions, and in a way that contributes to achieving the goals of the organization, and in light of these trends it can be said that the research made three contributions to developing management and measuring environmental performance through managerial accounting Environmental are:

The first: The research contributed to identifying three components of value that define and guide environmental economic efficiency, as it explains detailing the components of economic efficiency, which consist of three guides are sales margin, capital turnover and sustainable leverage, and the results of the research showed that environmental economic efficiency exceeds considerations of return on Traditional capital is from the perspective of the first two components, but it also depends on the value of the environmental resources used in the activity compared to the economic capital used (sustainable leverage).

According to value-based measurement models, the sustainable value approach and its foundation on the opportunity cost, this analysis compares the environmental economic efficiency of the company with the environmental economic efficiency of the market (Hahn et al., 2010) in order to reach environmental economic efficiency, where the highest environmental economic efficiency indicates To exceed the company's performance of market performance, and its activity generates sustainable value from its environmental resources, and by applying the same relationship to the three components of value related to environmental economic efficiency, and comparing it to the market average value; the analysis shows that companies in Area A achieve performance Or less for each of the various components of the environmental comparative market economic efficiency; and region (b) determine the value of components and routers that lead to high or low compared to the overall performance of creating value by using the higher efficiency of environmental resources and environmental economic market

Second: The analysis contributed to achieving a better understanding of the relationship between the various forms of resources, as the results demonstrated an integration between economic and environmental resources in creating value, and in this context, it was possible to clearly distinguish between creating economic value and creating sustainable value, and their relationship to each other, where economic value is focused In particular, to achieve the highest rate of return on capital, and linking it with the directives according to its impact on improving the rate of return on capital; while it is noted that companies that guarantee their business objectives of sustainability goals, adopt economic efficiency strategies such as profit and profit strategy (profit Environmental Simplicity and Profit (De Simone \& Popoff, 1998; Orsato, 2006) fall into one category, and finally, the approaches to improving shareholder value through environmental management are specifically focused on improving return on equity (Figge, 2005; Hart and Milstein In this context, the proposed model takes into account the return on other resources in tandem with the return on economic capital, as the value orientations of environmental economic efficiency improve the return on environmental resources along with the return on economic resources; in this logic, Value components and vectors of environmental and economic efficiency cover aspects only Economics and environmental alike

Value guides represent the variables that affect value creation, and value trends in relation to creating economic value can be determined by following the literature on shareholder value; which focused on discussing value trends that create economic value (Rappaport, 1986; Stewart, 1991); likewise The environmental extent of the value components can be determined according to the proposed model, through which efficiency guidelines for the use of environmental resources can be determined. Table (1) shows both the guides for creating economic value and creating sustainable value.

Drivers of economic value and sustainable value

\begin{tabular}{|c|c|l|}
\hline Sustainable Value & Economic Value & \multicolumn{1}{|c|}{ Drivers Value } \\
\hline+ & + & Sales margin \\
\hline+ & + & Sales growth \\
\hline$+/-$ & - & Investing in economic capital \\
\hline- & - & The cost of economic capital \\
\hline- & Unlearned & Use of environmental resources \\
\hline- & - & The cost of environmental resources \\
\hline
\end{tabular}

Third: The debate between the administrative and the current approaches regarding environmental accounting will continue (Burritt, 2012; Gray, 2002b; Owen, 2008; Parker, 2015, 2011); and even if there is a convergence or convergence between the two teams, there are still notes regarding the basic differences between them (Owen, 2008; Parker, 2011); and many researchers believe that the current interest in economic outcomes is greater than environmental or social concerns, whether in research or practical practices related to environmental accounting.

However, Parker (2015) emphasizes that environmental management accounting should strive to provide information that improves the quality of management decisions. Researchers who support this trend stress the necessity of integrating existing management accounting systems and environmental management accounting (Burritt, 2004). Accordingly, he sees both AlbeldaPérez et al. 2007)) as well (Henri and Journeault, 2010) that, in practice or in practice, there is an importance for providing environmental management accounting information to improve the environmental performance of companies; however, this approach faces criticism because it does not provide solutions to the administrative challenges facing its application.

In the context of trying to improve the quality of environmental management accounting information, there is a contradiction between the traditional and critical perspective, and they often appear to be contradictory, which will often lead to a contradictory situation; Standard administrative accounting 
systems, and to avoid the supporters 'opposition to the traditional entrance; however, some believe that environmental management is directed to achieve more integration and consistency with standard administrative accounting applications and create a greater link between them that will lead to a loss of realism and the ability to Footsteps of the financial results of standard activity

Some people may think that the research presented results that appear to be contradictory to overcome the difference in views between the traditional and critical inputs, given its establishment on the methodology of management according to value-based management, an intellectual school that has gained great momentum and interest in traditional management accounting (Ittner and Larcker, 2001; Malmi and Ikäheimo, 2003; Will, 2010). This methodology is expected to improve the environmental management accounting information, which contributes to improving the efficiency of the use of environmental resources. At the same time, the research does not focus on sub-environmental concerns in light of economic outcomes, but only concerned with creating economic value and creating environmental value.

The proposed approach in this research is not primarily intended to create value for shareholders, and thus it agrees with Gray's (2006) opinion in refusing to say that creating value for shareholders represents the appropriate ultimate goal of environmental accounting; rather than advocating for value creation for shareholders, logical foundations have been applied to create Value for shareholders from resources other than economic capital in light of the endeavor to create sustainable value or environmental value as a final goal; consequently, the proposed analysis will improve efficiency in the use of environmental resources to create sustainable value, as a result of providing information that helps to use environmental resources more efficiently than the level market

While the use of environmental resources contributes to maximizing value creation for shareholders through its secondary support to improve the economic outcomes of the enterprise, the proposed approach to measuring efficiency in the use of capital as a mentor is a key tool for raising environmental economic efficiency, and value trends and the reasons behind the efficiency of the enterprise's performance contribute to empowering those who take Decisions to distinguish between different situations, when environmental economic efficiency is the main driver of economic performance in the event of boom and recovery, and when environmental economic efficiency is the main driver through a strategy to reduce Avat; This distinction is especially relevant to the pursuit established to improve decision-making processes on environmental performance.

\section{CONCLUSION}

Managers are increasingly facing many challenges not only when they seek to create value for shareholders, but also when they seek to achieve higher economic and environmental efficiency; although in many cases companies that achieve higher value for shareholders are distinguished by their ability to achieve higher environmental economic efficiency, This relationship is not absolute, and managers wishing to achieve the previous goal must work to meet the challenges related to setting measures by which both the shareholder value and the sustainable value can be increased simultaneously; and given that the components and guidelines of shareholder value describe and define the elements that contribute to It has value for shareholders; if managers want to make decisions that lead to creating value from the use of economic and environmental resources, they must take into account the components and directives of environmental economic efficiency; and the three components of value, they help them determine whether their companies are above or below the market average in It is related to the economic and environmental field; at the same time, the comparison reveals the strength of the vectors that generate value from the use of economic, environmental and economic resources; the classification of the components of environmental economic efficiency into three components, and their comparison with mtos The performance of the sector; contributes to the classification of companies according to their ability to create value from the use of capital, environmental and economic illustrates the differences between the various companies performance (as shown in Table (1).

The importance of the proposed approach in this research is due to the fact that it provides a tool for managers to help them define the measures by which information can be provided that enables them to improve their competitive position in both economic and environmental aspects, and helps them to define the establishment's strategies in relation to creating value using economic and environmental resources; The actual situation of the company The value orientations proposed in this research help managers to improve value creation by using economic and environmental resources that move their company to a higher level of performance.

The philosophy of the analysis on which the research is based is distinguished by avoiding excessively simplistic analyzes that define a single assumption that applies to all strategies related to environmental and economic performance, where analyzing the company's performance in more detail in both fields (economic and environmental) increases the ability of managers to ensure the extent of compatibility Their strategy with the environmental and economic status of their companies.

\section{REFERENCES}

[1] Albelda-Pérez, E., Correa-Ruiz, C., Carrasco, Fenech, F., 2007. Environmental management systems as an embedding mechanism: a research note. Accounting, Auditing \& Accountability Journal 20, 403-422.

[2] Burritt, R.L., 2004. Environmental management accounting: roadblocks on the way to the green and pleasant land. Business Strategy and the Environment 13, 13-32.

[3] Burritt, R.L., 2012. Environmental performance accountability: planet, people, profits. Accounting, Auditing \& Accountability Journal 25, 370-405.

[4] Burritt, R.L., Hahn, T., Schaltegger, S., 2002. Towards a comprehen- sive framework for environmental management accounting-links between business actors and environmental management accounting tools. Australian Accounting Review 12, 39-50.

[5] Burritt, R.L., Saka, C., 2006. Environmental management accounting appli- cations and eco-efficiency: case studies from Japan. Journal of Cleaner Production 14, 1262-1275.

[6] Cha, K., Lim, S., Hur, T., 2008. Eco-efficiency approach for global warming in the context of Kyoto Mechanism. Ecological Economics 67, 274-280.

[7] Ciroth, A., 2009. Cost data quality considerations for ecoefficiency mea- sures. Ecological Economics 68, 15831590 .

[8] Figge, F., 2005. Value-based environmental management. From envi ronmental shareholder value to environmental option value. Corporate Social Responsibility and Environmental Management 12, 19-30. 
[9] Figge, F., Hahn, T., 2004. Sustainable value addedmeasuring corporate contributions to sustainability beyond eco-efficiency. Ecological Eco- nomics 48, 173-187.

[10] Figge, F., Hahn, T., 2015. The cost of sustainability capital and the creation of sustainable value by companies. Journal of Industrial Ecology 9, 47-58.

[11] Figge, F., Hahn, T., 2008. Sustainable investment analysis with the sustainable value approach - a plea and a methodology to overcome the instrumental bias in socially responsible investment research. Progress in Industrial Ecology 5 (3), 255-272.

[12] Frost, G.R., Wilmshurst, T.D., 2000. The Adoption of environment-related management accounting: an analysis of corporate environmental sensitivity. Accounting Forum 24, 344-365.

[13] Gray, R., 2002a. Of messiness, systems and sustainability: towards a more social and environmental finance and accounting. The British Accounting Review 34, 357-386.

[14] Gray, R., 2002b. The social accounting project and accounting organizations and society: Privileging engagement, imaginings, new accountings and pragmatism over critique? Accounting, Organizations and Society 27, 687-708.

[15] Gray, R., 2006. Social, environmental and sustainability reporting and organisational value creation? Whose value? Whose creation? Accounting, Auditing \& Accountability Journal 19, 793-819.

[16] Hahn, T.,Figge,F.,2011. Beyond the bounded instrumentality in current corporate sustainability research: toward an inclusive notion of profitability. Journal of Business Ethics 104, 325- 345.

[17] Hahn, T., Figge, F.,Liesen, A., Barkemeyer, R., 2010. Opportunity cost based analysis of corporate eco-efficiency: a methodology and its application to the CO2-efficiency of German companies. Journal of Environmental Management 91, $1997-2007$.

[18] Hart, S., Milstein, M., 2003. Creating sustainable value. Academy of Management Executive 17, 56-67.

[19] Henri, J.-F., Journeault, M., 2010. Eco-control: the influence of management control systems on environmental and economic performance. Accounting, Organizations and Society $35,63-80$.

[20] Horngren, C.T., Foster, G., Datar, S.M., 2016. Cost Accounting: A Managerial Emphasis. Prentice-Hall, Englwood Cliffs, NJ. Huppes, G., Ishikawa, M., 2005a. Eco-efficiency and its terminology. Journal of Industrial Ecology 9, 43-46

[21] Huppes, G., Ishikawa, M., 2005b.Aframework for quantified eco-efficiency analysis. Journal of Industrial Ecology 9, 25-41.

[22] Huppes, G., Ishikawa, M., 2009. Eco-efficiency guiding micro-level actions towards sustainability: ten basic steps for analysis. Ecological Economics 68, 1687-1700.

[23] Ittner, C.D., Larcker, D.F., 2001. Assessing empirical research in manage- rial accounting: a value-based management perspective. Journal of Accounting and Economics 32, 349-410.

[24] Keown, A.J., Martin, J.H., Petty, J.W., Scott, D.F., 2007.
Foundations of Finance. The Logic and Practice of Financial Management. Prentice Hall, Upper Saddle River.

[25] Lamberton, G., 2005. Sustainability accounting —a brief history and con- ceptual framework. Accounting Forum 29, $7-26$

[26] Malmi, T., Granlund, M., 2009. In search of management accounting theory. European Accounting Review 18, 597620

[27] Malmi, T., Ikäheimo, S., 2003. Value based management practices - some evidence from the field. Management Accounting Research 14, 235-254.

[28] Martin, J.D., Petty, J.W., 2017. Value Based Management: The Corporate Response to the Shareholder Revolution. Harvard Business School Press, Boston

[29] OICA, 2007. World Motor Vehicle Production. 2007 Production Statistics, Retrieved 23 June 2011, from www.oica.net/category/ production-statistics/2007-statistics/

[30] Orsato, R.J., 2006. Competitive environmental strategies when does it pay to be green? California Management Review 48, 127-143.

[31] Owen, D., 2008. Chronicles of wasted time? A personal reflection on the current state of, and future prospects for, social and environmental accounting research. Accounting, Auditing \& Accountability Journal 21, 240-267.

[32] Parker, L.D., 2015. Social and environmental accountability research: a view from the commentary box. Accounting, Auditing \& Accountability Journal 18, 842-860.

[33] Parker, L.D., 2011. Twenty-one years of social and environmental accountability research: a coming of age. Accounting Forum 35, 1-10.

[34] Rothenberg, S., Pil, F.K., Maxwell, J., 2001. Lean, green, and the quest for superior environmental performance. Production and Operations Management 10, 228-243.

[35] Saling, P., Kicherer, A., Dittrich-Krämer, B., Wittlinger, R., Zombik, W., Schmidt, I., Schrott, W., Schmidt, S., 2002. Eco-efficiency analysis by BASF: the method. International Journal of Life Cycle Assessment 7, 203-218.

[36] Schaltegger, S., Burritt, R., 2000. Contemporary Environmental Accounting: Issues, Concepts and Practice. Greenleaf, Sheffield.

[37] Stern, N., 2006. Review on the economics of climate change. HMT reasury, London.

[38] Stern, N., 2008. The economics of climate change. American Economic Review 98, 1-37.

[39] Sturm, A., Müller, K., Upasena, S., 2003. A Manual for Preparers and Users of Eco-efficiency Indicators: Conceptual Framework and Guidelines. United Nations Conference on Trade and Development, Geneva.

[40] Weißenberger, B.E., Angelkort, H., 2011. Integration of financial and management accounting systems: the mediating influence of a consistent financial language on controllership effectiveness. Management Accounting Research 22, 160-180.

[41] Will, S., 2010. Managerial discourse and the link between theory and prac- tice: from ROI to value-based management. Management Accounting Research 21, 95109. 